\title{
Impaired left ventricular systolic function and increased brachial-ankle pulse-wave velocity are independently associated with rapid renal function progression
}

\author{
Szu-Chia Chen ${ }^{1,2}$, Tsung-Hsien Lin ${ }^{3,4}$, Po-Chao Hsu ${ }^{3}$, Jer-Ming Chang ${ }^{1,2,5}$, Chee-Siong Lee ${ }^{3,4}$, \\ Wei-Chung Tsai ${ }^{2,3}$, Ho-Ming Su ${ }^{2,3,4}$, Wen-Chol Voon ${ }^{3,4}$ and Hung-Chun Chen ${ }^{1,5}$
}

Heart failure and increased arterial stiffness are associated with declining renal function. Few studies have evaluated the association between left ventricular ejection fraction (LVEF) and brachial-ankle pulse-wave velocity (baPWV) and renal function progression. The aim of this study was to assess whether LVEF $<40 \%$ and baPWV are associated with a decline in the estimated glomerular filtration rate (eGFR) and the progression to a renal end point of $\geqslant 25 \%$ decline in eGFR. This longitudinal study included 167 patients. The baPWV was measured with an ankle-brachial index-form device. The change in renal function was estimated by eGFR slope. The renal end point was defined as $\geqslant 25 \%$ decline in eGFR. Clinical and echocardiographic parameters were compared and analyzed. After a multivariate analysis, serum hematocrit was positively associated with eGFR slope, and diabetes mellitus, baPWV $(P=0.031)$ and $\operatorname{LEFF}<40 \%(P=0.001)$ were negatively associated with eGFR slope. Forty patients reached the renal end point. Multivariate, forward Cox regression analysis found that lower serum albumin and hematocrit levels, higher triglyceride levels, higher baPWV $(P=0.039)$ and $\operatorname{LVEF}<40 \%(P<0.001)$ were independently associated with progression to the renal end point. Our results show that $\operatorname{LEF}<40 \%$ and increased baPWV are independently associated with renal function decline and progression to the renal end point.

Hypertension Research (2011) 34, 1052-1058; doi:10.1038/hr.2011.95; published online 14 July 2011

Keywords: brachial-ankle pulse-wave velocity; left ventricular ejection fraction; renal function progression

\section{INTRODUCTION}

The risk for progression of renal function is contributed to by traditional risk factors (that is, hypertension, diabetes and dyslipidemia) and non-traditional risk factors, including cardiovascular disease and arterial stiffening. ${ }^{1,2} \mathrm{~A}$ failing heart can promote renal function progression through a variety of pathophysiological mechanisms, including hemodynamic factors, systemic neurohormonal factors, drug treatment and anemia. ${ }^{3,4}$ In addition, increased arterial stiffness has been reported to have a role in renal function progression. ${ }^{5-7}$ Previous studies have shown that several measures of arterial stiffness (that is, augmentation index, radial-dorsalis pedis pulse-wave velocity (PWV) and aortic PWV) are independent risk factors for the deterioration of renal function in patients with chronic kidney disease. ${ }^{5-7} \mathrm{~A}$ clinical device, the ankle-brachial index-form (VP1000; Colin, Komaki, Japan), has been developed to record pulse waves of the brachial and posterior tibial arteries automatically and simultaneously using an automated oscillometric method. Using this device, we can easily and automatically calculate the brachial-ankle PWV (baPWV). ${ }^{8}$ The baPWV has been reported to be a good marker of arterial stiffness. ${ }^{9}$

Progressive decline in renal function has been significantly associated with high cardiovascular morbidity and mortality, independent of baseline renal function. ${ }^{10,11}$ Therefore, identifying patients with rapid renal function progression for aggressive treatment intervention is important in disease attenuation and prolonged survival. However, studies to evaluate whether echocardiographic parameters and baPWV are independently associated with a decline in renal function are limited. Accordingly, the aim of this study was to assess whether echocardiographic parameters and baPWV are independently associated with a decline in renal function and progression to the

${ }^{1}$ Division of Nephrology, Department of Internal Medicine, Kaohsiung Medical University Hospital, Kaohsiung Medical University, Kaohsiung, Taiwan; ${ }^{2}$ Department of Internal Medicine, Kaohsiung Municipal Hsiao-Kang Hospital, Kaohsiung Medical University, Kaohsiung, Taiwan; ${ }^{3}$ Division of Cardiology, Department of Internal Medicine, Kaohsiung Medical University Hospital, Kaohsiung Medical University, Kaohsiung, Taiwan; ${ }^{4}$ Faculty of Medicine, College of Medicine, Kaohsiung Medical University, Kaohsiung, Taiwan and ${ }^{5}$ Faculty of Renal Care, College of Medicine, Kaohsiung Medical University, Kaohsiung, Taiwan

Correspondence: Dr H-M Su, Department of Internal Medicine, Kaohsiung Municipal Hsiao-Kang Hospital, Kaohsiung Medical University, 482, Shan-Ming Rd, Hsiao-Kang Dist, 812 Kaohsiung, Taiwan.

E-mail: cobeshm@seed.net.tw

Received 8 December 2010; revised 7 March 2011; accepted 3 April 2011; published online 14 July 2011 
renal end point of $\geqslant 25 \%$ decline in the estimated glomerular filtration rate (eGFR).

\section{METHODS}

\section{Study patients}

The study subjects were randomly selected from patients who underwent echocardiographic examinations at Kaohsiung Municipal Hsiao-Kang Hospital. Patients with significant aortic or mitral valve disease, atrial fibrillation, hemodialysis and inadequate image visualization were excluded. We did not include all the patients consecutively because the baPWV was measured within 5 min of the completion of the echocardiographic examination. In addition, those patients $(n=24)$ with follow-up times of $<6$ months were excluded to avoid an incomplete observation of changes in renal function. A total of 191 patients were enrolled from January to September 2007, and they were followed until May 2010. In all, 24 patients with fewer than three eGFR measurements during the follow-up period were excluded, and a final total of 167 patients (mean age $57.5 \pm 13.7$ years old, 95 men and 72 women) were included. The protocol was approved by our institutional review board, and all enrolled patients gave written informed consent.

\section{Evaluation of cardiac structure and function}

The echocardiographic examination was performed by the same experienced sonographer using transthoracic echocardiography (Vivid 7; General Electric Medical Systems, Horten, Norway), with the participant respiring quietly in the left decubitus position. Two-dimensional and two-dimensionally guided M-mode images were recorded from the standardized views. Left ventricular mass was calculated using the Devereux-modified method. ${ }^{12}$ The left ventricular mass index (LVMI) was calculated by dividing left ventricular mass by body surface area. Left ventricular hypertrophy (LVH) was considered to be present when LVMI exceeded 134 and $110 \mathrm{~g} \mathrm{~m}^{-2}$ for men and women, respectively. ${ }^{13}$ The Doppler sample volume was placed at the tips of the mitral leaflets to obtain left ventricular inflow waveforms from the apical fourchamber view. All sample volumes were positioned with ultrasonic beam alignment to flow. Tissue Doppler imaging was obtained with the sample volume placed at the lateral corner of the mitral annulus from the apical fourchamber view. The wall filter settings were adjusted to exclude high-frequency signals, and the gain was minimized. Left ventricular ejection fraction (LVEF) was measured by the modified Simpson's method. The raw ultrasonic data were recorded and analyzed offline by a cardiologist, blinded to the other data, using EchoPAC software (GE Medical Systems, Horten, Norway). The echocardiographic data were obtained from three consecutive beats, and the data were then averaged to yield the mean value for further analysis.

\section{Measurement of baPWV}

Within $5 \mathrm{~min}$ of the completion of the echocardiographic examination, the baPWVs were measured with an ankle-brachial index-form device (VP1000; Colin). ${ }^{8}$ For measuring baPWVs, pulse waves obtained from the brachial and tibial arteries were recorded simultaneously, and the transmission time, which was defined as the time interval between the initial increase in brachial and tibial waveforms, was determined. The transmission distance from the arm to each ankle was calculated according to body height. The values of baPWVs were automatically computed as the transmission distance divided by the transmission time. After obtaining bilateral baPWV values, the greater value was used for analysis.

\section{Collection of demographic, medical and laboratory data}

Demographic and medical data, including age, gender, smoking history (ever $v s$. never) and comorbid conditions, were obtained from medical records or from interviews with patients. Body mass index was calculated as the ratio of weight in kilograms divided by the square of height in meters. Laboratory data were measured from fasting blood samples using an autoanalyzer (Roche Diagnostics GmbH, Mannheim, Germany and COBAS Integra 400, Roche Diagnostics $\mathrm{GmbH}$ ). Serum creatinine was measured by the compensated Jaffé (kinetic alkaline picrate) method with a Roche/Integra 400 Analyzer (Roche Diagnostics, $\mathrm{GmbH}$ ), using a calibrator traceable to isotope-dilution mass spectrometry. ${ }^{14}$ The value of eGFR was calculated using the four-variable equation in the Modification of Diet in Renal Disease study. ${ }^{15}$ Proteinuria was examined by dipstick (Hema-Combistix, Bayer Diagnostics, Dublin, Ireland). A test result of $1+$ or more was defined as positive. Blood and urine samples were obtained within 1 month of enrollment. In addition, information regarding patient medications, including angiotensin-converting enzyme inhibitors, angiotensin II receptor blockers, $\beta$-blockers (including nonselective $\beta$-blockers and selective $\beta_{1}$-blockers), calcium channel blockers and diuretics during the study period, was obtained from medical records.

\section{Assessment of decline in renal function and definition of renal end point}

The decline in renal function was assessed by the eGFR slope, defined as the regression coefficient between eGFR and time in units of $\mathrm{ml} \mathrm{min}^{-1}$ per $1.73 \mathrm{~m}^{2}$ per year. At least three eGFR measurements were required to estimate the eGFR slope. Any reduction $>3 \mathrm{ml} \mathrm{min}^{-1}$ per $1.73 \mathrm{~m}^{2}$ per year, that is, a slope more negative than $-3 \mathrm{ml} \mathrm{min}^{-1}$ per $1.73 \mathrm{~m}^{2}$ per year $(<-3)$, was considered to reflect progression of renal function; otherwise, it was considered non-progressive. ${ }^{11}$ Additionally, the renal end point was defined as a $\geqslant 25 \%$ decline in eGFR since enrollment.

\section{Statistical analysis}

Statistical analysis was performed using SPSS, version 12.0 (SPSS, Chicago, IL, USA) for Windows. Data are expressed as percentages, the mean \pm s.d., or the mean \pm s.e.m. The differences between groups were evaluated using a $\chi^{2}$ test for categorical variables or by an independent $t$-test for continuous variables. The relationship between two continuous variables was assessed using a bivariate correlation method (Pearson's correlation). Linear regression analysis was used to identify the factors associated with the decline in kidney function. The time to the renal end point of $\geqslant 25 \%$ decline in eGFR and covariates of risk factors were modeled using the Cox proportional hazards model. Age, gender and the significant variables in univariate analysis were selected for multivariate analysis. A difference was considered significant if the $P$-value was $<0.05$.

\section{RESULTS}

A comparison of baseline characteristics between patients with progressive $\left(<-3 \mathrm{ml} \mathrm{min}^{-1}\right.$ per $1.73 \mathrm{~m}^{2}$ per year) and non-progressive $\left(\geqslant-3 \mathrm{ml} \mathrm{min}^{-1}\right.$ per $1.73 \mathrm{~m}^{2}$ per year $)$ decline in eGFR $\left(\mathrm{ml} \mathrm{min}^{-1}\right.$ per $1.73 \mathrm{~m}^{2}$ per year) is shown in Table 1 . The value of the eGFR slope of all patients was $-0.97 \pm 4.42 \mathrm{ml} \mathrm{min}^{-1}$ per $1.73 \mathrm{~m}^{2}$ per year. The average number of serum creatinine measurements during the follow-up period was $7.0 \pm 4.5$ (range 3 to 20 ). In all, 34 patients $(20.4 \%$ ) were affected by both diabetes and hypertension. Compared with patients with non-progressive decline in eGFR, patients with progressive decline in eGFR had an older age, higher prevalence of a history of diabetes mellitus (DM) and congestive heart failure, lower serum albumin, lower hematocrit, higher uric acid, higher baPWVs, and a greater likelihood of receiving angiotensin-converting enzyme inhibitor and/or angiotensin II receptor blocker therapy. In addition, patients in the progressive group had a higher left ventricular endsystolic volume, higher LVMI, higher prevalence of LVH, higher prevalence of LVEF $<40 \%$, higher peak early transmitral filling wave velocity (E), lower early diastolic velocity of lateral mitral annulus $(\mathrm{Ea})$, lower late diastolic velocity of lateral mitral annulus (Aa) and higher E/Ea.

Table 2 shows the determinants of the rate of renal function decline in all patients. In the univariate analysis, the eGFR slope had a significantly positive correlation with serum albumin, serum hematocrit, and Ea and a negative correlation with age, DM, congestive heart failure, heart rate, fasting glucose, baPWVs, LVEF $<40 \%$, E, peak late transmitral filling wave velocity (A) and E/Ea. After multiple stepwise linear regression analysis, the eGFR slope was correlated independently with $\mathrm{DM}(\beta=-0.199, P=0.019)$, hematocrit $(\beta=0.224$, 
Table 1 Comparison of baseline characteristics between patients with progressive $\left(<-3 \mathrm{ml} \mathrm{min}^{-1}\right.$ per $1.73 \mathrm{~m}^{2}$ per year) and non-progressive $\left(\geqslant-3 \mathrm{ml} \mathrm{min}^{-1}\right.$ per $1.73 \mathrm{~m}^{2}$ per year) rates of eGFR decline $\left(\mathrm{ml} \mathrm{min}-1\right.$ per $1.73 \mathrm{~m}^{2}$ per year)

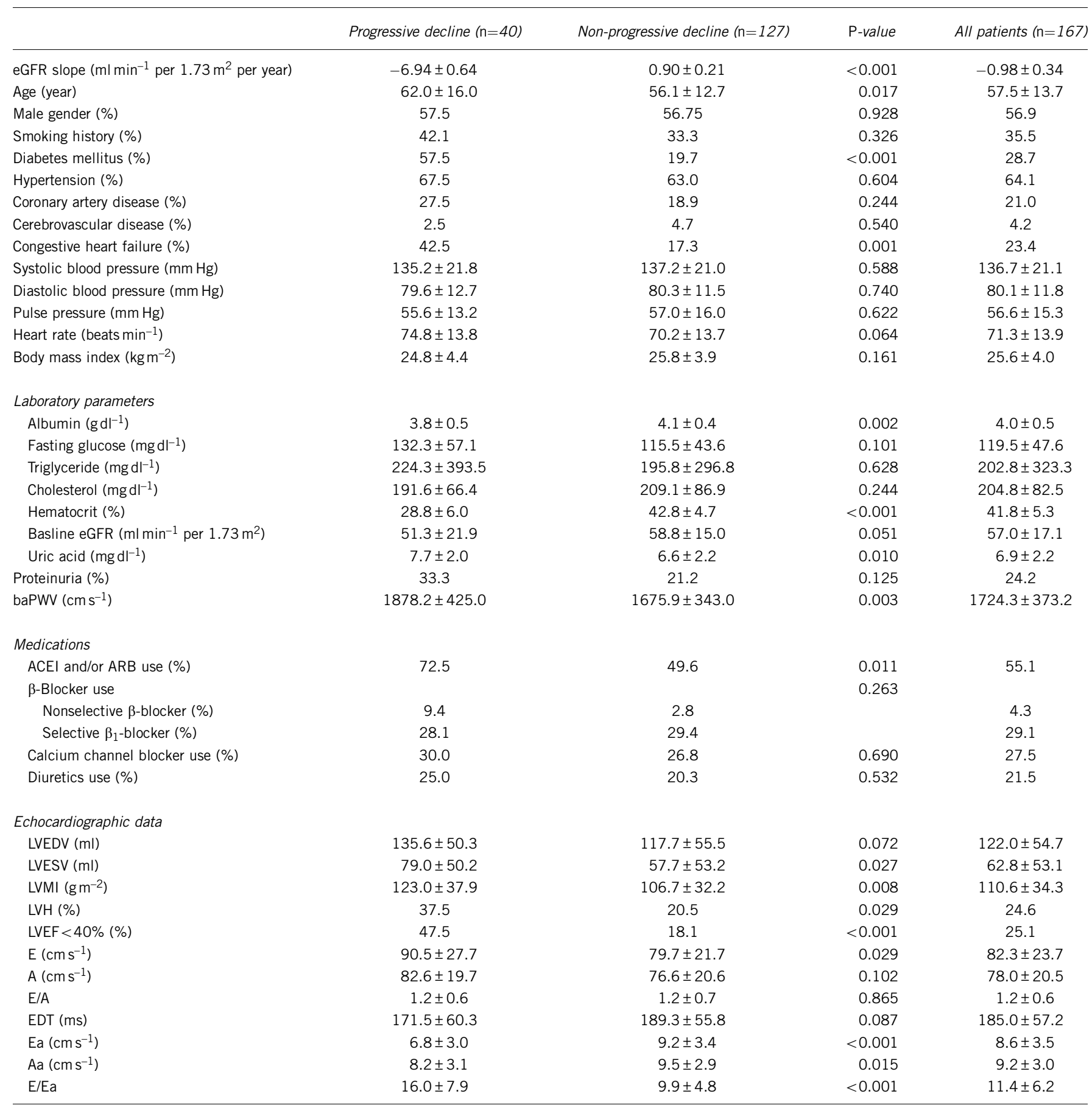

Abbreviations: A, peak late transmitral filling wave velocity; Aa, late diastolic velocity of lateral mitral annulus; ACEI, angiotensin converting enzyme inhibitor; ARB, angiotensin II receptor blocker; baPWV, brachial-ankle pulse wave velocity; E, peak early transmitral filling wave velocity; Ea, early diastolic velocity of lateral mitral annulus; EDT, E-wave deceleration time; eGFR, estimated glomerular filtration rate; LVEDV, left ventricular end-diastolic volume; LVEF, left ventricular ejection fraction; LVESV, left ventricular end-systolic volume; LVH, left ventricular hypertrophy; LVMI, left ventricular mass index.

$P=0.006)$, baPWVs $(\beta=-0.176, P=0.031)$ and $\mathrm{LVEF}<40 \% \quad(\beta=$ $-0.274, P=0.001)$. In Figure 1 , the eGFR slopes in patients with LVEF $<40 \%$ and LVEF $\geqslant 40 \%$ are $-2.85 \pm 0.92$ vs. $-0.35 \pm 0.32 \mathrm{ml} \mathrm{min}^{-1}$ per $1.73 \mathrm{~m}^{2}$ per year (mean \pm s.e.m., $P=0.013$ ), respectively.

The mean follow-up period was $30.7 \pm 12.4$ months. During the period of follow-up, three patients entering hemodialysis and six patients with mortality were recorded (5.4\%). However, all the patients reached the renal end point earlier than they received dialysis, or they died. Table 3 shows a Cox proportional hazards regression analysis for progression to the renal end point of $\geqslant 25 \%$ decline in eGFR. Univariate regression analysis shows that the hazard ratio (HR) of the baPWV was $1.001(P=0.010)$ and of LVEF $<40 \%$ was 6.409 $(P<0.001)$. In addition, other variables, including smoking, the presence of $\mathrm{DM}$, congestive heart failure, increased heart rate, 
Table 2 Determinants of eGFR slope in study patients

\begin{tabular}{|c|c|c|c|c|}
\hline \multirow[b]{2}{*}{ Parameter } & \multicolumn{2}{|c|}{ Univariate } & \multicolumn{2}{|c|}{ Multivariate (stepwise) } \\
\hline & $\begin{array}{l}\text { Standardized } \\
\text { coefficient } \beta\end{array}$ & $\begin{array}{c}\mathrm{P}- \\
\text { value }\end{array}$ & $\begin{array}{l}\text { Standardized } \\
\text { coefficient } \beta\end{array}$ & $\begin{array}{c}\mathrm{P}- \\
\text { value }\end{array}$ \\
\hline Age (year) & -0.168 & 0.030 & - & - \\
\hline Male gender (\%) & -0.015 & 0.846 & - & - \\
\hline Smoking history (\%) & -0.102 & 0.208 & - & - \\
\hline Diabetes mellitus (\%) & -0.353 & $<0.001$ & -0.199 & 0.019 \\
\hline Hypertension (\%) & 0.005 & 0.946 & - & - \\
\hline Coronary artery disease (\%) & -0.039 & 0.618 & - & - \\
\hline Cerebrovascular disease (\%) & 0.128 & 0.099 & - & - \\
\hline Congestive heart failure (\%) & -0.163 & 0.032 & - & - \\
\hline Systolic blood pressure $(\mathrm{mm} \mathrm{Hg})$ & -0.057 & 0.463 & - & - \\
\hline Diastolic blood pressure $(\mathrm{mm} \mathrm{Hg})$ & -0.028 & 0.716 & - & - \\
\hline Pulse pressure $(\mathrm{mm} \mathrm{Hg})$ & -0.057 & 0.465 & - & - \\
\hline Heart rate (beats $\mathrm{min}^{-1}$ ) & -0.188 & 0.015 & - & - \\
\hline Body mass index $\left(\mathrm{kg} \mathrm{m}^{-2}\right)$ & 0.107 & 0.170 & - & - \\
\hline Laboratory parameters & & & - & - \\
\hline Albumin $\left(\mathrm{g} \mathrm{dl}^{-1}\right)$ & 0.248 & 0.004 & - & - \\
\hline Fasting glucose $\left(\mathrm{mg} \mathrm{dl}^{-1}\right)$ & -0.230 & 0.003 & - & - \\
\hline Triglyceride $\left(\mathrm{mg} \mathrm{dl}^{-1}\right)$ & -0.057 & 0.469 & - & - \\
\hline Cholesterol (mg dl$\left.{ }^{-1}\right)$ & 0.047 & 0.549 & - & - \\
\hline Hematocrit (\%) & 0.306 & $<0.001$ & 0.224 & 0.006 \\
\hline $\begin{array}{l}\text { Basline eGFR } \\
\left(\mathrm{ml} \mathrm{min}{ }^{-1} \text { per } 1.73 \mathrm{~m}^{2}\right)\end{array}$ & 0.081 & 0.299 & - & - \\
\hline Uric acid $\left(\mathrm{mgdl}^{-1}\right)$ & -0.128 & 0.122 & - & - \\
\hline Proteinuria (\%) & -0.136 & 0.090 & - & - \\
\hline $\mathrm{baPWV}\left(\mathrm{cm} \mathrm{s}^{-1}\right)$ & -0.326 & $<0.001$ & -0.176 & 0.031 \\
\hline \multicolumn{5}{|l|}{ Medications } \\
\hline ACEI and/or ARB use (\%) & -0.120 & 0.123 & - & - \\
\hline \multicolumn{5}{|l|}{$\beta$-Blocker (vs. no usage) } \\
\hline Nonselective $\beta$-blocker (\%) & 0.007 & 0.948 & - & - \\
\hline Selective $\beta_{1}$-blocker (\%) & -0.015 & 0.863 & - & - \\
\hline Calcium channel blocker use (\%) & -0.055 & 0.483 & - & - \\
\hline Diuretics use (\%) & -0.011 & 0.893 & - & - \\
\hline Echocardiographic data & 0.112 & 0.180 & - & - \\
\hline LVEDV (ml) & 0.194 & 0.021 & - & - \\
\hline LVESV (ml) & 0.321 & $<0.001$ & - & - \\
\hline LVMI $\left(\mathrm{g} \mathrm{m}^{-2}\right)$ & 0.315 & $<0.001$ & - & - \\
\hline LVH (\%) & -0.094 & 0.229 & - & - \\
\hline LVEF $<40 \%(\%)$ & -0.246 & 0.001 & -0.274 & 0.001 \\
\hline $\mathrm{E}\left(\mathrm{cm} \mathrm{s}^{-1}\right)$ & -0.035 & 0.654 & - & - \\
\hline$A\left(\mathrm{~cm} \mathrm{~s}^{-1}\right)$ & -0.156 & 0.044 & - & - \\
\hline $\mathrm{E} / \mathrm{A}$ & 0.071 & 0.359 & - & - \\
\hline EDT (ms) & 0.073 & 0.349 & - & - \\
\hline $\mathrm{Ea}\left(\mathrm{cm} \mathrm{s}^{-1}\right)$ & 0.267 & $<0.001$ & - & - \\
\hline $\mathrm{Aa}\left(\mathrm{cm} \mathrm{s}^{-1}\right)$ & -0.008 & 0.920 & - & - \\
\hline $\mathrm{E} / \mathrm{Ea}$ & -0.282 & $<0.001$ & - & - \\
\hline
\end{tabular}

Values expressed as standardized coefficient $\beta$. Abbreviations are the same as in Table 1.

decreased serum albumin, increased fasting glucose, increased triglycerides, decreased hematocrit, decreased baseline eGFR, increased uric acid, the presence of proteinuria, the use of angiotensin-converting enzyme inhibitor and/or angiotensin II receptor blocker, the use of diuretics, increased left ventricular end-diastolic volume (LVEDV), increased left ventricular end-systolic volume, increased LVMI, the presence of $\mathrm{LVH}$, increased $\mathrm{E}$, decreased $\mathrm{Ea}$, decreased $\mathrm{Aa}$ and

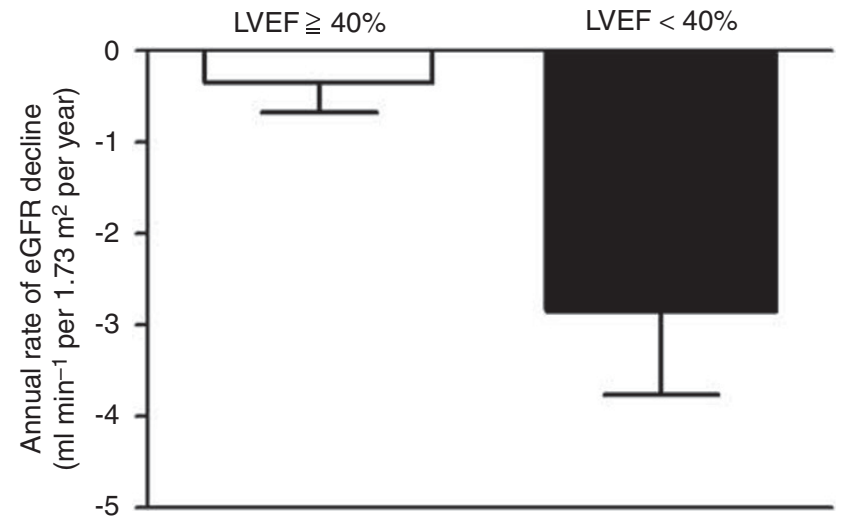

Figure 1 Annual rate of estimated glomerular filtration rate (eGFR) decline in patients with depressed left ventricular systolic function (LVEF $<40 \%$ ) and preserved left ventricular systolic function (LVEF $\geqslant 40 \%)(-2.85 \pm 0.92$ vs. $-0.35 \pm 0.32$ (mean \pm s.e.m.), $P=0.013$ ).

increased $\mathrm{E} / \mathrm{Ea}$, were associated with a significant increase in progression to the renal end point. In the multivariate forward analysis, serum triglyceride levels (hazards ratio (HR), 1.002; $P=0.001$ ), baPWVs (HR, $1.001 ; P=0.039)$, and $\mathrm{LVEF}<40 \%(\mathrm{HR}, 10.870 ; P<0.001)$ were positively associated and serum albumin $(\mathrm{HR}, 0.149 ; P<0.001)$ and serum hematocrit levels $(\mathrm{HR}, 0.805 ; P<0.001)$ were negatively associated with progression to the renal end point. Figure 2 illustrates the adjusted Cox regression survival curves for renal end point-free survival in patients with $\mathrm{LVEF}<40$ vs. $\geqslant 40 \%$. Patients with LVEF $<40 \%$ had worse renal end point-free survival than those with LVEF $\geqslant 40 \%(P<0.001)$

We also analyzed the subgroup of patients who did not have diabetes $(n=119)$. After multivariate analysis, the eGFR slope had a significantly negative correlation with $\mathrm{E} / \mathrm{Ea}(\beta=-0.376, P<0.001)$, and higher $\mathrm{E} / \mathrm{Ea}$ was associated with a significant increase in progression to renal end point ( $\mathrm{HR}, 1.317 ; P=0.019)$. However, increased baPWVs and LVEF $<40 \%$ were not associated with eGFR slope or with progression to renal end point in non-diabetic patients.

\section{DISCUSSION}

In this study, we evaluated the impact of echocardiographic parameters and baPWVs on the rate of renal function decline and progression to the renal end point of $\geqslant 25 \%$ decline in eGFR. We found that $\mathrm{LVEF}<40 \%$ and increased baPWVs were independently associated with the eGFR slope and with reaching the renal end point. This result may indicate that there is some interaction not only between the heart and kidney (the so-called cardiorenal syndrome) but also between the vessels and kidneys. Therefore, cardiorenal syndrome may be extended to cardiovascular renal syndrome.

As cardiac dysfunction portends a poor prognosis in renal failure and vice versa, there has been a recent surge of interest in identifying the exact pathophysiological connection between the failing heart and kidneys. Rocho et al. ${ }^{3,4}$ presented a new classification of the cardiorenal syndrome, with five subtypes that reflect the primary and secondary pathophysiology, the time frame, and simultaneous cardiac and renal co-dysfunction secondary to systemic disease. Type 2 cardiorenal syndrome is characterized by chronic abnormalities in cardiac function (for example, chronic congestive heart failure), which cause worsening renal function. ${ }^{3,4}$ The mechanisms of progressive renal function decline in patients with cardiac dysfunction include such factors as chronic renal hypoperfusion, subclinical inflammation, endothelial dysfunction, accelerated atherosclerosis, increased renal 
Table 3 Predictors of progression to renal end point ( $\geqslant 25 \%$ decline in eGFR) using Cox proportional hazards model

\begin{tabular}{|c|c|c|c|c|}
\hline \multirow[b]{2}{*}{ Parameter } & \multicolumn{2}{|c|}{ Univariate } & \multicolumn{2}{|c|}{ Multivariate (forward) } \\
\hline & $H R(95 \% \mathrm{Cl})$ & P-value & $H R(95 \% \mathrm{Cl})$ & P-value \\
\hline Male vs. female & $1.364(0.719-2.588)$ & 0.342 & - & - \\
\hline Smoking (ever vs. never) & $2.435(1.275-4.651)$ & 0.007 & - & - \\
\hline Diabetes mellitus & $6.193(3.227-11.886)$ & $<0.001$ & - & - \\
\hline Cerebrovascular disease & $0.046(0.000-36.217)$ & 0.366 & - & - \\
\hline Congestive heart failure & $4.422(2.366-8.267)$ & $<0.001$ & - & - \\
\hline Systolic blood pressure (per 1 mm Hg) & $0.994(0.979-1.010)$ & 0.453 & - & - \\
\hline Diastolic blood pressure (per $1 \mathrm{~mm} \mathrm{Hg}$ ) & $0.997(0.970-1.025)$ & 0.843 & - & - \\
\hline Pulse pressure (per $1 \mathrm{~mm} \mathrm{Hg}$ ) & $0.991(0.970-1.012)$ & 0.387 & - & - \\
\hline Heart rate (per 1 beats $\mathrm{min}^{-1}$ ) & $1.035(1.015-1.055)$ & 0.001 & - & - \\
\hline Fasting glucose (per $1 \mathrm{mg} \mathrm{dl}^{-1}$ ) & $1.007(1.002-1.012)$ & 0.004 & - & - \\
\hline Triglyceride (per $1 \mathrm{mg} \mathrm{dl}^{-1}$ ) & $1.001(1.000-1.001)$ & 0.013 & $1.002(1.001-1.002)$ & 0.001 \\
\hline Cholesterol (per $1 \mathrm{mg} \mathrm{dl}^{-1}$ ) & $1.000(0.996-1.004)$ & 0.999 & - & - \\
\hline Hematocrit (per 1\%) & $0.866(0.823-0.912)$ & $<0.001$ & $0.805(0.734-0.881)$ & $<0.001$ \\
\hline Basline eGFR (per $1 \mathrm{ml} \mathrm{min}^{-1}$ per $1.73 \mathrm{~m}^{2}$ ) & $0.946(0.930-0.963)$ & $<0.001$ & - & - \\
\hline Uric acid (per $1 \mathrm{mg} \mathrm{dl}^{-1}$ ) & $1.337(1.184-1.509)$ & $<0.001$ & - & - \\
\hline Proteinuria & $4.440(2.344-8.412)$ & $<0.001$ & - & - \\
\hline baPWV (per $1 \mathrm{~cm} \mathrm{~s}^{-1}$ ) & $1.001(1.000-1.002)$ & 0.010 & $1.001(1.000-1.002)$ & 0.039 \\
\hline \multicolumn{5}{|l|}{ Medications } \\
\hline ACEI and/or ARB use & $2.698(1.318-5.522)$ & 0.007 & - & - \\
\hline LVESV (per $1 \mathrm{ml}$ ) & $1.011(1.006-1.015)$ & $<0.001$ & - & - \\
\hline LVMI (per $1 \mathrm{~g} \mathrm{~m}^{-2}$ ) & $1.018(1.010-1.025)$ & $<0.001$ & - & - \\
\hline LVH & $2.994(1.603-5.589)$ & 0.001 & - & - \\
\hline LVEF $<40 \%$ & $6.409(3.388-12.123)$ & $<0.001$ & $10.840(4.563-25.896)$ & $<0.001$ \\
\hline $\mathrm{E}\left(\operatorname{per} 1 \mathrm{~cm} \mathrm{~s}^{-1}\right)$ & $1.019(1.006-1.033)$ & 0.003 & - & - \\
\hline$A\left(\operatorname{per} 1 \mathrm{~cm} \mathrm{~s}^{-1}\right)$ & $1.008(0.992-1.024)$ & 0.346 & - & - \\
\hline $\mathrm{E} / \mathrm{A}($ per 1$)$ & $1.265(0.832-1.925)$ & 0.272 & - & - \\
\hline EDT (per $1 \mathrm{~ms}$ ) & $0.996(0.990-1.002)$ & 0.187 & - & - \\
\hline $\mathrm{Ea}\left(\right.$ per $\left.1 \mathrm{~cm} \mathrm{~s}^{-1}\right)$ & $0.786(0.707-0.875)$ & $<0.001$ & - & - \\
\hline $\mathrm{Aa}\left(\right.$ per $\left.1 \mathrm{~cm} \mathrm{~s}^{-1}\right)$ & $0.836(0.751-0.931)$ & 0.001 & - & - \\
\hline $\mathrm{E} / \mathrm{Ea}($ per 1$)$ & $1.108(1.070-1.147)$ & $<0.001$ & - & - \\
\hline
\end{tabular}

Values express as hazard ratios (HR) and 95\% confidence interval (CI). Abbreviations are the same as in Table 1.

vascular resistance, systemic neurohormonal factors, pharmacotherapies and anemia. ${ }^{3,4}$ Shlipak et al. ${ }^{16}$ studied the association of clinical cardiovascular disease with renal function decline in the elderly. They found that the diagnosis of permanent heart failure was an independent predictor of rapid renal function decline (defined by an annular eGFR loss $>3 \mathrm{ml} \mathrm{min}^{-1}$ per $1.73 \mathrm{~m}^{2}$ ). In our study, we also demonstrated a significant association between LVEF $<40 \%$ and renal function progression, which indicates that a failing heart may promote renal function decline.
Cerasola et al. ${ }^{17}$ demonstrated that LVMI had a significant association with eGFR and that the prevalence of LVH was greater in subjects with lower values of eGFR than in subjects with normal renal function. In this study, patients with a progressive decline in eGFR had a higher LVMI and a greater prevalence of LVH than patients with non-progressive declines in eGFR, which was consistent with the previous findings. E/Ea has been shown to be a good predictor of left ventricular filling pressure. ${ }^{18}$ Patients with a high E/Ea may have a high volume status, thereby increasing renal efferent pressure, 


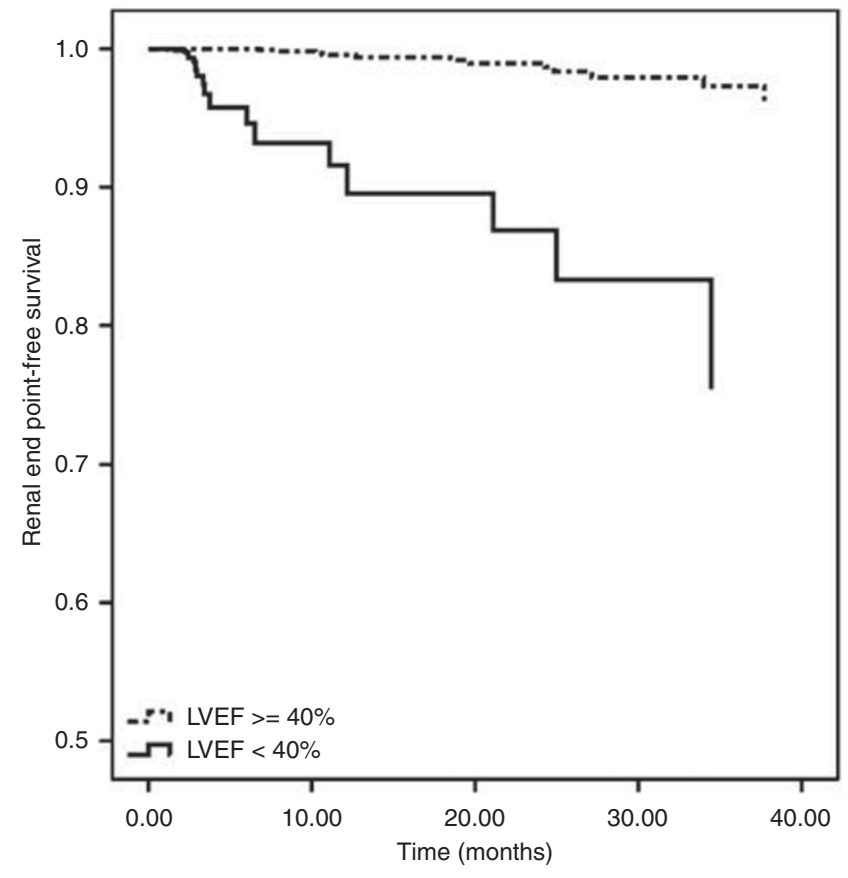

Figure 2 Adjusted renal end point-free survival by left ventricular ejection fraction (LVEF) $<40$ vs. $\geqslant 40 \%$ (hazard ratio (HR), 10.870; $95 \%$ confidence interval, 4.563 to $25.896, P<0.001$ ).

decreasing renal blood flow and finally causing progressive renal function decline. ${ }^{3}$ Similarly, our patients with progressive decline in eGFR had a higher E/Ea than patients with non-progressive declines in eGFR. In addition, our subgroup analysis also found that a higher $\mathrm{E} / \mathrm{Ea}$ was independently associated with renal function decline and progression to the renal end point in non-diabetic patients. The higher preload status may have contributed to the rapid decline in renal function.

Increased arterial stiffness was reported to be associated with decreased eGFR in cross-sectional studies. ${ }^{19}$ Three longitudinal studies using different measurement methods of arterial stiffness (that is, augmentation index, radial-dorsalis pedis PWVs and aortic PWVs) showed that increased arterial stiffness was an independent predictor of renal function progression in patients with chronic kidney disease. ${ }^{5-7}$ They explained their finding citing the greater transmission of elevated systemic blood pressure to the glomerular capillaries, thereby exacerbating glomerular hypertension caused by increased arterial stiffness. Although our measurement method was different from theirs, we also revealed a significant association between baPWVs and rapid eGFR decline. Additionally, the renal resistive index, which correlates significantly with the effective renal plasma flow, the renal vascular resistance and the filtration rate in chronic renal failure patients, is used as a pulse-waved Doppler measurement of downstream renal artery resistance. ${ }^{20} \mathrm{An}$ increased renal resistive index of the renal arteries is associated with greater severity of systemic arterial stiffness. ${ }^{21}$ Radermacher et al..$^{22,23}$ evaluated the relationship between this ultrasonographic parameter and the progression of renal disease and found that an increased renal resistive index was associated with rapid renal function decline in patients with chronic renal disease and with poor renal allograft survival in renal transplants. Therefore, patients with greater arterial stiffness may have a higher renal resistive index and, thereby, a more rapid decline in renal function.

Inflammation and catabolism have a role in the pathophysiology of chronic heart failure. ${ }^{24,25}$ Progression of renal disease may be asso- ciated with an increased prevalence of inflammation, which is one risk factor for accelerated atherosclerosis. ${ }^{26,27}$ Malnutrition may worsen patient outcomes by aggravating existing inflammation and heart failure and by accelerating atherosclerosis. ${ }^{28}$ Low serum albumin levels have been regarded as indicating malnutrition status. Hypoalbuminemia has been reported to contribute to the progression of renal function. ${ }^{29}$ Our results consistently showed that decreased serum albumin levels were independently associated with progression to the renal end point of $\geqslant 25 \%$ decline in eGFR.

In this study, we showed that a lower hematocrit level was associated with a more rapid decline of renal function and rapid progression to the renal end point. Previous studies have demonstrated that anemia is an independent risk factor for rapid renal function decline and for the progression of kidney disease to end-stage renal disease or death. ${ }^{30}$ The possible mechanism by which anemia can accelerate renal function progression may be hypoxia. Hypoxia caused by anemia may impair oxygen delivery to tubular cells, thereby resulting in chronic ischemia and nephron loss. ${ }^{31,32}$ In addition, hypoxia may increase the activity of renal interstitial fibroblasts and activate the sympathetic and renin-angiotensin-aldosterone system, which can cause increased interstitial fibrosis and kidney damage. ${ }^{33,34}$

There were several limitations to our study. The number and interval of serum creatinine measurements for measuring the eGFR slope varied in each patient, and thus, the calculation of eGFR slope was not uniform in every subject. However, to decrease the chance of an unreliable estimation of eGFR slope, we excluded 24 patients with fewer than three eGFR measurements during the follow-up period and patients $(n=24)$ with follow-up times of $<6$ months.

In conclusion, our results show that $\mathrm{LVEF}<40 \%$ and increased baPWVs were independently associated with rapid renal function progression. Screening patients by means of LVEF and baPWVs may help to identify a high-risk group of patients in rapid renal function decline.

\section{CONFLICT OF INTEREST}

The authors declare no conflict of interest.

\section{ACKNOWLEDGEMENTS}

The research presented in this article was supported by a grant from Kaohsiung Municipal Hsiao-Kang Hospital (kmhk-99-025), Kaohsiung Medical University, Kaohsiung, Taiwan.

1 Go AS, Chertow GM, Fan D, McCulloch CE, Hsu CY. Chronic kidney disease and the risks of death, cardiovascular events, and hospitalization. N Engl J Med 2004; 351: 1296-1305

2 Tonelli M, Wiebe N, Culleton B, House A, Rabbat C, Fok M, McAlister F, Garg AX. Chronic kidney disease and mortality risk: a systematic review. J Am Soc Nephrol 2006; 17: 2034-2047.

3 Bock JS, Gottlieb SS. Cardiorenal syndrome: new perspectives. Circulation 2010; 121: 2592-2600.

4 Ronco C. Cardiorenal syndromes: definition and classification. Contrib Nephrol 2010; 164: 33-38

5 Ford ML, Tomlinson LA, Chapman TP, Rajkumar C, Holt SG. Aortic stiffness is independently associated with rate of renal function decline in chronic kidney disease stages 3 and 4. Hypertension 2010; 55: 1110-1115.

6 Taal MW, Sigrist MK, Fakis A, Fluck RJ, McIntyre CW. Markers of arterial stiffness are risk factors for progression to end-stage renal disease among patients with chronic kidney disease stages 4 and 5. Nephron Clin Pract 2007; 107: c177-c181.

7 Takenaka T, Mimura T, Kanno Y, Suzuki H. Qualification of arterial stiffness as a risk factor to the progression of chronic kidney diseases. Am J Nephrol 2005; 25: 417-424.

8 Yamashina A, Tomiyama H, Takeda K, Tsuda H, Arai T, Hirose K, Koji Y, Hori S, Yamamoto $Y$. Validity, reproducibility, and clinical significance of noninvasive brachialankle pulse wave velocity measurement. Hypertens Res 2002; 25: 359-364.

9 Lehmann ED. Clinical value of aortic pulse-wave velocity measurement. Lancet 1999; 354: $528-529$ 
10 Khan NA, Ma I, Thompson CR, Humphries K, Salem DN, Sarnak MJ, Levin A. Kidney function and mortality among patients with left ventricular systolic dysfunction. J Am Soc Nephrol 2006; 17: 244-253.

11 Shlipak MG, Katz R, Kestenbaum B, Siscovick D, Fried L, Newman A, Rifkin D, Sarnak MJ. Rapid decline of kidney function increases cardiovascular risk in the elderly. J Am Soc Nephrol 2009; 20: 2625-2630.

12 Devereux RB, Alonso DR, Lutas EM, Gottlieb GJ, Campo E, Sachs I, Reichek N. Echocardiographic assessment of left ventricular hypertrophy: comparison to necropsy findings. Am J Cardiol 1986; 57: 450-458.

13 Devereux RB. Detection of left ventricular hypertrophy by M-mode echocardiography. Anatomic validation, standardization, and comparison to other methods. Hypertension 1987; 9: II19-II26.

14 Vickery S, Stevens PE, Dalton RN, van Lente F, Lamb EJ. Does the ID-MS traceable MDRD equation work and is it suitable for use with compensated Jaffe and enzymatic creatinine assays? Nephrol Dial Transplant 2006; 21: 2439-2445.

15 Levey AS, Bosch JP, Lewis JB, Greene T, Rogers N, Roth D. A more accurate method to estimate glomerular filtration rate from serum creatinine: a new prediction equation. Modification of Diet in Renal Disease Study Group. Ann Intern Med 1999; 130: 461-470.

16 Shlipak MG, Katz R, Kestenbaum B, Fried LF, Siscovick D, Sarnak MJ. Clinical and subclinical cardiovascular disease and kidney function decline in the elderly. Atherosclerosis 2009; 204: 298-303.

17 Cerasola G, Nardi E, Mule G, Palermo A, Cusimano P, Guarneri M, Arsena R, Giammarresi G, Carola Foraci A, Cottone S. Left ventricular mass in hypertensive patients with mild-to-moderate reduction of renal function. Nephrology (Carlton) 2010; 15: 203-210.

18 Ommen SR, Nishimura RA, Appleton CP, Miller FA, Oh JK, Redfield MM, Tajik AJ. Clinical utility of Doppler echocardiography and tissue Doppler imaging in the estimation of left ventricular filling pressures: a comparative simultaneous Doppler-catheterization study. Circulation 2000; 102: 1788-1794.

19 Chen JH, Chen SC, Liu WC, Su HM, Chen CY, Mai HC, Chou MC, Chang JM. Determinants of peripheral arterial stiffness in patients with chronic kidney disease in southern Taiwan. Kaohsiung J Med Sci 2009; 25: 366-373.

20 Petersen LJ, Petersen JR, Ladefoged SD, Mehlsen J, Jensen HA. The pulsatility index and the resistive index in renal arteries in patients with hypertension and chronic renal failure. Nephrol Dial Transplant 1995; 10: 2060-2064.
21 Ohta Y, Fujii K, Arima H, Matsumura K, Tsuchihashi T, Tokumoto M, Tsuruya K, Kanai $\mathrm{H}$, Iwase $\mathrm{M}$, Hirakata $\mathrm{H}$, lida $\mathrm{M}$. Increased renal resistive index in atherosclerosis and diabetic nephropathy assessed by Doppler sonography. J Hypertens 2005; 23: 1905-1911.

22 Radermacher J, Ellis S, Haller $\mathrm{H}$. Renal resistance index and progression of renal disease. Hypertension 2002; 39: 699-703.

23 Radermacher J, Mengel M, Ellis S, Stuht S, Hiss M, Schwarz A, Eisenberger U, Burg M, Luft FC, Gwinner W, Haller $\mathrm{H}$. The renal arterial resistance index and renal allograft survival. N Engl J Med 2003; 349: 115-124.

24 Anker SD, von Haehling S. Inflammatory mediators in chronic heart failure: an overview. Heart 2004; 90: 464-470.

25 Park CW, Shin YS, Kim CM, Lee SY, Yu SE, Kim SY, Choi EJ, Chang YS, Bang BK. Increased C-reactive protein following hemodialysis predicts cardiac hypertrophy in chronic hemodialysis patients. Am J Kidney Dis 2002; 40: 1230-1239.

26 Panichi V, Migliori M, De Pietro S, Taccola D, Bianchi AM, Norpoth M, Metelli MR, Giovannini L, Tetta C, Palla R. C reactive protein in patients with chronic renal diseases. Ren Fail 2001; 23: 551-562.

27 Ross R. Atherosclerosis-an inflammatory disease. N Engl J Med 1999; 340: $115-126$.

28 Levin NW, Handelman GJ, Coresh J, Port FK, Kaysen GA. Reverse epidemiology: a confusing, confounding, and inaccurate term. Semin Dial 2007; 20: 586-592.

29 Silverstein DM. Inflammation in chronic kidney disease: role in the progression of renal and cardiovascular disease. Pediatr Nephrol 2009; 24: 1445-1452.

30 Bansal N, Tighiouart H, Weiner D, Griffith J, Vlagopoulos P, Salem D, Levin A, Sarnak MJ. Anemia as a risk factor for kidney function decline in individuals with heart failure. Am J Cardiol 2007; 99: 1137-1142.

31 Fine LG, Bandyopadhay D, Norman JT. Is there a common mechanism for the progression of different types of renal diseases other than proteinuria? Towards the unifying theme of chronic hypoxia. Kidney Int Supp/ 2000; 75: S22-S26.

32 Nangaku M. Hypoxia and tubulointerstitial injury: a final common pathway to end-stage renal failure. Nephron Exp Nephrol 2004; 98: e8-12.

33 Rossert J, Fouqueray B, Boffa JJ. Anemia management and the delay of chronic renal failure progression. J Am Soc Nephrol 2003; 14: S173-S177.

34 Katz AM. The cardiomyopathy of overload: an unnatural growth response in the hypertrophied heart. Ann Intern Med 1974; 121: 363-371. 